\title{
Probiotic Properties and In vitro Biosafety Assessment of Human Breast Milk Isolates
}

\author{
Dharti K. Kurkutia, Nirali Mistry and Mitesh Dwivedi*
}

C.G. Bhakta Institute of Biotechnology, Faculty of Science, Uka Tarsadia University, Maliba Campus, Gopal Vidyanagar, Bardoli-Mahuva Road, Tarsadi, Bardoli, Dist. Surat - 394 350, Gujarat, India.

\begin{abstract}
Human milk can be an important source for obtaining potential probiotics strains for newborns in order to establish the beneficial gut microbial community and development of immune system. The aim of the study was to explore potential human breast milk probiotics and to carry out their in vitro biosafety assessment. The study obtained three isolates namely, $\mathrm{SP}_{1} \mathrm{~B}_{1} \mathrm{~B}_{2} \mathrm{Enr}$ and $\mathrm{SP}_{1}$ which showed potential probiotic activities compared to standard probiotic Lactobacillus plantarum. In addition, these isolates were found to be safe through various in vitro biosafety aspects. The molecular identification by16srDNA sequencing revealed that $\mathrm{SP}_{1} \mathrm{~B}_{\text {and }} \mathrm{B}_{2}$ Enr belong to Bacillus cereus (MK210172) and Staphylococcus epidermidis (MK210234), respectively. For the first time, the study suggests that these bacterial strains may come in the category of probiotics and can be considered further after in vivo biosafety assessments.

Keywords: Probiotics; Biosafety assessment; Human breast milk; 16srDNA sequencing.
\end{abstract}

*Correspondence: mitesh_dwivedi@yahoo.com; +91-2625-254122.

(Received: 10 May 2019; accepted: 13 June 2019)

Abbreviations: Biogenic amines (BA); Mucin 2 (MUC2); Cell-free neutralized supernatants (CFNS); Muller-Hinton Agar (MHA); Gastrointestinal tract (GIT).

Citation: Dharti K. Kurkutia, Nirali Mistry and Mitesh Dwivedi, Probiotic Properties and In Vitro Biosafety Assessment of Human Breast Milk Isolates, J Pure Appl Microbiol., 2019; 13(2): 1121-1134. doi: 10.22207/JPAM.13.2.51

(c) The Author(s) 2019. Open Access. This article is distributed under the terms of the Creative Commons Attribution 4.0 International License which permits unrestricted use, sharing, distribution, and reproduction in any medium, provided you give appropriate credit to the original author(s) and the source, provide a link to the Creative Commons license, and indicate if changes were made. 


\section{INTRODUCTION}

The WHO has defined Probiotics as 'Live microorganisms which when administered in adequate amounts confer $a$ health benefit on the host $^{\prime \prime}$. (FAO/WHO, 2002). In particular, Lactobacilli and Bifidobacteria have been implicated as probiotics in many food supplements ${ }^{2,3}$. Probiotics promote health physiological functions by surviving and colonizing into the gut ${ }^{4}$. This bacterial colonization into the gut may regulate the immune system and health status of the infants $5^{5,6}$. The first bacterial colonizers in breast-fed infants are facultative anaerobes that include Enterococci, Staphylococci, Streptococci, Lactobacilli and Enterobacteria as well as strict anaerobe $B i$ dobacteria?.

The breast milk protects mother and infants from many infectious diseases and is a natural source of potential probiotics strains ${ }^{8}$. Earlier, the milk from breast was considered as sterile; however, later many studies suggested that the milk contains many beneficial bacteria which enhance neonate's immune system and protect against many gut disorders. The probiotics isolated from breast milk have shown to possess antimicrobial compounds which inhibit the growth of pathogenic organisms. ${ }^{9}$ The common bacterial genera found in breast milk are Bifidobacterium, Lactobacillus, Clostridium, Ralstonia, Staphylococcus, and Streptococcus. ${ }^{8}$

A potential probiotic strain must possess good acid tolerance and bile tolerance properties in addition to the antimicrobial properties against pathogenic bacteria. In addition, the good cell surface hydrophobicity $\%$ of probiotics ensures attachment to the gut epithelium which enhances the host interaction. ${ }^{10}$ Moreover, the bacterial auto-aggregation results in gut bacterial homeostasis ${ }^{11}$ and the co-aggregation property of probiotics is also crucial for prevention of colonization of host surfaces by pathogens ${ }^{12}$. Apart from these potential probiotic characteristics they must have GRAS (Generally Regarded as Safe) property as a safety concern for consumption by the host. The assessment of safety aspects of probiotics can be addressed by in vitro and in vivo tests. In particular, the in vitro safety assessment includes antibiotic resistance, mucin degradation, biogenic amines production, deconjugation of bile salts, hemolytic activity and gelatinase production properties of the probiotic test cultures.

Since, the mother's milk is beneficial to the neonate and may possess such kind of probiotics; the present study was focused to explore potential probiotic bacteria of human breast milk samples and to investigate the probiotic properties along with their in vitro biosafety aspects.

\section{MATERIALS \& METHODS Collection of Sample}

Total four human breast milk samples were collected from healthy volunteer mothers. The mothers had full-term normal pregnancy without any maternal perinatal problems. The study plan was carried out in accordance with the 1964 Helsinki Declaration and also approved by the Institutional-Human Research Ethical Committee (IHREC), Maliba Pharmacy College, Uka Tarsadia University, Bardoli, Gujarat, India. All women volunteers were aware about importance of the study and written consent was obtained.

\section{Isolation of probiotic Bacteria}

The milk samples were serially diluted with peptone water $\left(10^{-1}, 10^{-2} \& 10^{-3}\right)$ and the aliquots were plated on MRS agar. All the plates were incubated at $37^{\circ} \mathrm{C}$ for 3 days.

Evaluation of probiotic characteristics of the isolates

\section{Acid and Bile Tolerance activity}

The isolates obtained were further grown in MRS-broth and cells were harvested. The cells were suspended in PBS ( $\mathrm{pH}$ 7. 4); which then subjected to serial dilutions using PBS $(\mathrm{pH} 3.0)$ and kept for different time durations ( $0 \mathrm{hr}, 2 \mathrm{hrs}$, $4 \mathrm{hrs}$ and $24 \mathrm{hrs}$ ). The aliquots were plated on MRS agar followed by incubation at $37^{\circ} \mathrm{C}$ for $24-48 \mathrm{hrs}$. The CFU/ml was calculated for each of these plates and the growth on MRS agar indicated the acid tolerance of the isolates.

The MRS agar was prepared using different concentrations $(0.3 \%, 0.5 \%, 1.0 \%, 1.5 \%)$ of Cholic acid. The serial dilution of cell suspension was prepared and aliquots were plated on Cholic acid-MRS agar followed by incubation at $37^{\circ} \mathrm{C}$ for 24-48 hrs. CFU/ml was then calculated for each of these plates and the growth on Cholic acidMRS Agar was used to designate the bile tolerant property.

Antibacterial Activity

The cell-free neutralized supernatants 
(CFNS) were used for assessing the antibacterial activity. The cultures were grown in MRS-broth for $18 \mathrm{hrs}$ at $37^{\circ} \mathrm{C}$ to obtain CFNS. The supernatant $\mathrm{pH}$ was adjusted to 6. 5-7. 0 using $1 \mathrm{~N} \mathrm{NaOH}$. The supernatant is then heated $a t 100^{\circ} \mathrm{C}$ for $5 \mathrm{~min}$. and cooled down followed by storage at $-20^{\circ} \mathrm{C}$. The neutralized CFNS were then checked for its antibacterial activity against Staphylococcus aureus, Pseudomonas aeruginosa, Escherichia coli, and Proteus vulgaris using the agar well diffusion method.

\section{Cell surface hydrophobicity}

The isolates were grown in MRS-broth; cells were harvested, washed with PBS and suspended in five $\mathrm{ml}$ Phosphate Urea Magnesium (PUM) buffer. Initial O. D. $\left(O D_{\text {Initial }}\right)$ of the cell suspension was taken at $610 \mathrm{~nm}$. Three $\mathrm{ml}$ bacterial suspension was mixed with one $\mathrm{ml}$ of respective hydrocarbons followed by incubation at $37^{\circ} \mathrm{C}$ for $10 \mathrm{~min}$. It was then vortexed for 120 secs and kept undisturbed at $37^{\circ} \mathrm{C}$ for one hour to allow phase separation. The aqueous phase was carefully removed after one hour with a Pasteur pipette. The O. D. was measured using spectrophotometer and hydrophobicity percentage $(\mathrm{H} \%)$ was calculated by the following formula ${ }^{13}$ :

$H \%=(1-A 1 / A 0) \times 100$ [A1 is initial 0.

D. and $A O$ is final O. D. ]

\section{Auto aggregation property}

The cells were freshly grown in MRS-broth at $37^{\circ} \mathrm{C}$, harvested and washed twice with PBS. The cells were then suspended in PBS and initial absorbance $\left(\mathrm{Abs}_{\text {initial }}\right)$ was taken at $600 \mathrm{~nm}$. The cell suspension was centrifuged and pellet was resuspended in equal volume of broth removed at first step. The mixture was then allowed to stand for $2 \mathrm{hrs}$ at $37^{\circ} \mathrm{C}$. Further, one $\mathrm{ml}$ of the upper suspension was taken to measure the absorbance $\left(\mathrm{Abs}_{\text {final }}\right.$ ) by using broth as reference. The aggregation \% was calculated by the following formula ${ }^{14}$ :

Aggregation \%= $\left(A b s_{\text {initial }}-A b_{\text {final }}\right) / A b s_{\text {final }} \times 100$ Co-aggregation property

The indicator organisms were grown in nutrient broth and the isolates were grown in MRS-broth at $37^{\circ} \mathrm{C}$. The cells were pelleted down, washed twice with PBS and resuspended in PBS. The O. D. was taken at $600 \mathrm{~nm}$. The probiotics were mixed with pathogenic organisms followed by incubation at $37^{\circ} \mathrm{C}$ for $24 \mathrm{hrs}$. Further, the absorbance was taken at $600 \mathrm{~nm}$ and the percentage of co-aggregation was calculated as [(Apathogen + Aprobiotic)/2 - (Amix)/(Apathogen + Aprobiotic)/2] ' 100 [Apathogen and Aprobiotic refers to absorbance in the tubes containing either the pathogen or the probiotics respectively; Amix refers to absorbance of the mixture of both at $24 \mathrm{hrs}]^{15}$.

Assessment of in vitro biosafety aspects of isolates

Biogenic amines and Gelatinase production

The biogenic amines production of isolates was assessed as mentioned previously ${ }^{16}$. The isolates were grown overnight at $37^{\circ} \mathrm{C}$ in MRSbroth (supplemented with $2 \mathrm{~g} / \mathrm{l}$ final concentration of different amino acids such as histidine, arginine, phenylalanine, tryptophan, and lysine). After 3-5 days of incubation, $0.2 \mathrm{ml}$ of the suspension was mixed with two $\mathrm{ml}$ of modified decarboxylase broth followed by incubation for 3 days under anaerobic condition. The presence of biogenic amines was indicated when purple color changes to yellow and again turned to purple.

Gelatinase production of the isolates was assessed as described by Eatson \& Gasson ${ }^{17}$. The isolates were grown in MRS-broth at $37^{\circ} \mathrm{C}$ and streaked on Todd-Hewitt agar plates containing $30 \mathrm{gm} /$ liter of gelatin. The plates were placed at $4^{\circ} \mathrm{C}$ for 5 hours after the incubation. The protein hydrolysis was assessed by zones of turbidity around the colonies.

\section{Mucin degradation and Hemolytic activity}

The isolates were grown in MRS-broth at $37^{\circ} \mathrm{C}$. Ten micro liter of viable cultures were inoculated on the surface of medium $B$ with some modifications. All the plates were incubated at $37^{\circ} \mathrm{C}$ for 72 hours under anaerobic condition. Mucin degradation was confirmed upon staining with $0.1 \% \mathrm{w} / \mathrm{v}$ amido black in $3.5 \mathrm{M}$ acetic acid (for $30 \mathrm{~min}$ ) and washing with 1. 2M acetic acid which resulted in a discolored zone around the colony.

The hemolytic activity was checked as mentioned previously ${ }^{18}$. The isolates were grown in MRS-broth at $37^{\circ} \mathrm{C}$ and then streaked onto blood agar plates followed by incubation of $24-48 \mathrm{hrs}$. After incubation period colonies were checked for clear zones to be reported as $\alpha$-hemolysis, $\beta$-hemolysis or $\gamma$-hemolysis.

Bile salts deconjugation and Antibiotic resistance Bile salts deconjugation was assessed as 
mentioned previously ${ }^{19}$. The isolates were grown in MRS-broth at $37^{\circ} \mathrm{C}$ and then inoculated on the MRS agar plates (supplemented with $0.05 \% \mathrm{w} / \mathrm{v}$ L-cysteine and $0.5 \% \mathrm{w} / \mathrm{v}$ sodium salts). All the plates were incubated at $37^{\circ} \mathrm{C}$ for $72 \mathrm{hrs}$ under anaerobic condition. The bile salt deconjugation was confirmed by the presence of bile acid precipitation around the colonies.

The disc diffusion method was used for assessing antibiotic resistance of the isolates ${ }^{20}$. The freshly grown cultures were spreaded onto Muller-Hinton Agar (MHA) plates. The antibiotic multidiscs were then placed and plates were incubated at $37^{\circ} \mathrm{C}$ for 2 days. The zone of inhibition surrounding the disc was measured in $\mathrm{mm}$, and the isolates were tagged as susceptible, moderately susceptible and resistant to the respective antibiotics.

\section{Molecular identification}

The selected probiotic isolates were subjected to genomic DNA isolation and 16srDNA PCR was performed using the forward primer: 5' AGAGTTTGATCCTGGCTCAG3' and reverse primer: 5'AAGGAGGTGATCCAGCCGCA3'. The PCR products were then sent for $16 \operatorname{srDNA}$ sequencing. The DNA sequences were BLAST from the existence microbial DNA database and Phylogenetic trees were evaluated.

\section{Statistical Analysis}

For the cell surface hydrophobicity, auto-aggregation and co-aggregation properties of the isolates, one way ANOVA was carried out using Duncan analysis test in IBM SPSS Statistics for Windows, version XX (IBM Corp. , Armonk, NY, USA). For each sample, the results were expressed as mean $\pm S D$.

\section{RESULTS}

Evaluation of the isolates for probiotic properties Total 114 isolates were obtained from the human breast milk samples. The isolates were further subjected to assessment of their probiotic characteristics.

\section{Acid and Bile Tolerance Activity of Isolates}

The present study isolates were found to be resistant to $\mathrm{pH} 3.0$ during $0 \mathrm{hr}, 2 \mathrm{hrs}, 4 \mathrm{hrs}$ and $24 \mathrm{hrs}$. However, seven isolates were found to possess good acid tolerance at $\mathrm{pH} 3.0$ as indicated by CFU/ml (Table 1 ). Moreover, it was found that the isolate $B_{2} E N r$ showed maximum acid tolerance as compared to that of standard probiotic $L$. plantarum.

The bile tolerance property was showed by all the isolates at $0.5 \%$ Cholic acid whereas, some of the isolates showed tolerance upto $1 \%$ Cholic acid (Table 1). Interestingly, $\mathrm{SP}_{1} \mathrm{~S}$ isolate was found to be more bile tolerant and capable of tolerating $1.5 \%$ Cholic acid as compared to $L$. plantarum.

\section{Antibacterial activity of Isolates}

All the isolates showed inhibitory effect on the growth of all test microorganisms used except $\mathrm{SP}_{2}$ and $\mathrm{SP}_{1} \mathrm{M}$ which did not show antibacterial activity against $P$. aeruginosa and $P$. vulgaris respectively; as suggested by the diameter of inhibitory zones (Table 2). However,

Table 1. Acid and Bile tolerance properties of the different isolates

\begin{tabular}{|c|c|c|c|c|c|c|c|c|}
\hline \multirow[t]{2}{*}{ Isolates } & \multicolumn{4}{|c|}{$\mathrm{CFU} / \mathrm{ml}(\mathrm{pH} 3)$} & \multicolumn{4}{|c|}{ Bile concentration (Cholic acid) } \\
\hline & $0 \mathrm{hr}$ & $2 \mathrm{hrs}$ & $4 \mathrm{hrs}$ & $24 \mathrm{hrs}$ & $0.3 \%$ & $0.5 \%$ & $1.0 \%$ & $1.5 \%$ \\
\hline $\begin{array}{l}\text { L. } \\
\text { plantarum }\end{array}$ & $289 \times 10^{5}$ & $237 \times 10^{5}$ & $175 \times 10^{5}$ & $112 \times 10^{5}$ & $245.5 \times 10^{4}$ & $166 \times 10^{4}$ & $148 \times 10^{4}$ & $<30$ \\
\hline $\mathrm{SP}_{1}$ & $128 \times 10^{5}$ & $118 \times 10^{5}$ & $93.3 \times 10^{5}$ & $76 \times 10^{5}$ & $88 \times 10^{4}$ & $90 \times 10^{4}$ & $97 \times 10^{4}$ & $\begin{array}{l}\text { No } \\
\text { growth }\end{array}$ \\
\hline $\mathrm{SP}_{2}$ & $175 \times 10^{5}$ & $141 \times 10^{5}$ & $108.3 \times 10^{5}$ & $67 \times 10^{5}$ & $228 \times 10^{4}$ & $222 \times 10^{4}$ & $103 \times 10^{4}$ & $<30$ \\
\hline $\mathrm{SP}_{3}^{2}$ & $140 \times 10^{5}$ & $103 \times 10^{5}$ & $87 \times 10^{5}$ & $42 \times 10^{5}$ & $150 \times 10^{4}$ & $88 \times 10^{4}$ & No growth & $\begin{array}{l}\text { No } \\
\text { growth }\end{array}$ \\
\hline $\mathrm{SP}_{1} \mathrm{~B}$ & $109.3 \times 10^{5}$ & $98 \times 10^{5}$ & $81.6 \times 10^{5}$ & $57 \times 10^{5}$ & $293 \times 10^{4}$ & $152 \times 10^{4}$ & $78 \times 10^{4}$ & $\begin{array}{l}\text { No } \\
\text { growth }\end{array}$ \\
\hline $\mathrm{SP}_{1} \mathrm{M}$ & $168 \times 10^{5}$ & $102 \times 10^{5}$ & $74 \times 10^{5}$ & $28 \times 10^{5}$ & $148 \times 10^{4}$ & $52 \times 10^{4}$ & $32 \times 10^{4}$ & $<30$ \\
\hline $\mathrm{SP}_{1}^{1} \mathrm{~S}$ & $282 \times 10^{5}$ & $191 \times 10^{5}$ & $89 \times 10^{5}$ & $39 \times 10^{5}$ & $235 \times 10^{4}$ & $202 \times 10^{4}$ & $107 \times 10^{4}$ & $37 \times 10^{4}$ \\
\hline $\mathrm{B}_{2}$ Enr & $190 \times 10^{5}$ & $180 \times 10^{5}$ & $177 \times 10^{5}$ & $163 \times 10^{5}$ & $89 \times 10^{4}$ & $123 \times 10^{4}$ & $124 \times 10^{4}$ & $<30$ \\
\hline
\end{tabular}


E. coli was found to be highly susceptible to the antibacterial action of $\mathrm{SP}_{1}, \mathrm{SP}_{2}, \mathrm{SP}_{3}, \mathrm{SP}_{1} \mathrm{~B}, \mathrm{SP}_{1} \mathrm{M}$ and $\mathrm{B}_{2}$ Enr. $\mathrm{SP}_{1}$, The $\mathrm{SP}_{1} \mathrm{~B}$ and $\mathrm{SP}_{1} \mathrm{~S}_{\text {exhibited maximum }}$ antibacterial activity against $P$. vulgaris whereas $\mathrm{SP}_{1}, \mathrm{SP}_{1} \mathrm{~S}$ and $\mathrm{B}_{2}$ Enr showed good antibacterial activity against $P$. aeruginosa. The $S$. aureus growth was highly susceptible to antibacterial action of $\mathrm{SP}_{1} \mathrm{M}, \mathrm{SP}_{1}, \mathrm{SP}_{2}, \mathrm{SP}_{1} \mathrm{~S}$ and $\mathrm{B}_{2}$ Enr.

Cell surface hydrophobicity, Auto-aggregation and Co-aggregation properties of Isolates

The evaluation of hydrophobicity $\%$ of all the isolates suggested that most of the probiotic isolates possess good surface hydrophobicity as compared to standard probiotic $L$. plantarum (Table 3). However, few isolates showed poor adhesion ability as suggested by less hydrophobicity \%. The $\mathrm{SP}_{3}$ isolate showed the highest hydrophobicity with

Table 2. Antibacterial activity of isolates against different indicator microorganisms

\begin{tabular}{lcccc}
\hline Isolates & \multicolumn{4}{c}{$\begin{array}{c}\text { Diameter of zone of inhibition (in } \\
\mathrm{mm} \text { ) }\end{array}$} \\
\cline { 2 - 5 } & $\begin{array}{c}E . \\
\text { against indicator bacteria }\end{array}$ & $\begin{array}{c}\text { P. } \\
\text { aeruginosa }\end{array}$ & $\begin{array}{c}\text { S. } \\
\text { aureus }\end{array}$ & $\begin{array}{c}\text { P. } \\
\text { vulgaris }\end{array}$ \\
\hline $\mathrm{SP}_{1}$ & 25 & 13 & 19 & 29 \\
$\mathrm{SP}_{2}$ & 25 & 00 & 15 & 13 \\
$\mathrm{SP}_{3}$ & 23 & 8 & 10 & 11 \\
$\mathrm{SP}_{1} \mathrm{~B}$ & 24 & 7 & 9 & 25 \\
$\mathrm{SP}_{1} \mathrm{M}$ & 24 & 7 & 25 & 00 \\
$\mathrm{SP}_{1} \mathrm{~S}$ & 19 & 12 & 16 & 18 \\
$\mathrm{~B}_{2}$ Enr & 28 & 10 & 16 & 12 \\
\hline
\end{tabular}

xylene and $B_{2}$ Enr showed highest hydrophobicity with chloroform.

Further, the auto-aggregation property was assessed and analyzed by Duncan analysis test which indicated that all the isolates possess good auto-aggregation property $(p<0.05$; Table 3). Interestingly, the $\mathrm{SP}_{1} \mathrm{~S}$ was found to possess highest auto-aggregation property among all the isolates and as compared to the standard probiotic L. plantarum.

The co-aggregation property was also found to be good for all the isolates with pathogenic test organisms $(p<0.05$; Table 3$)$. The isolates $\mathrm{SP}_{1}, \mathrm{SP}_{3}, \mathrm{SP}_{1} \mathrm{M}$, and $\mathrm{SP}_{1} \mathrm{~S}$ showed highest co-aggregation \% with Pseudomonas aeruginosa which was comparable to that of $L$. plantarum. However, the statistical analysis showed that $\mathrm{SP}_{2}$

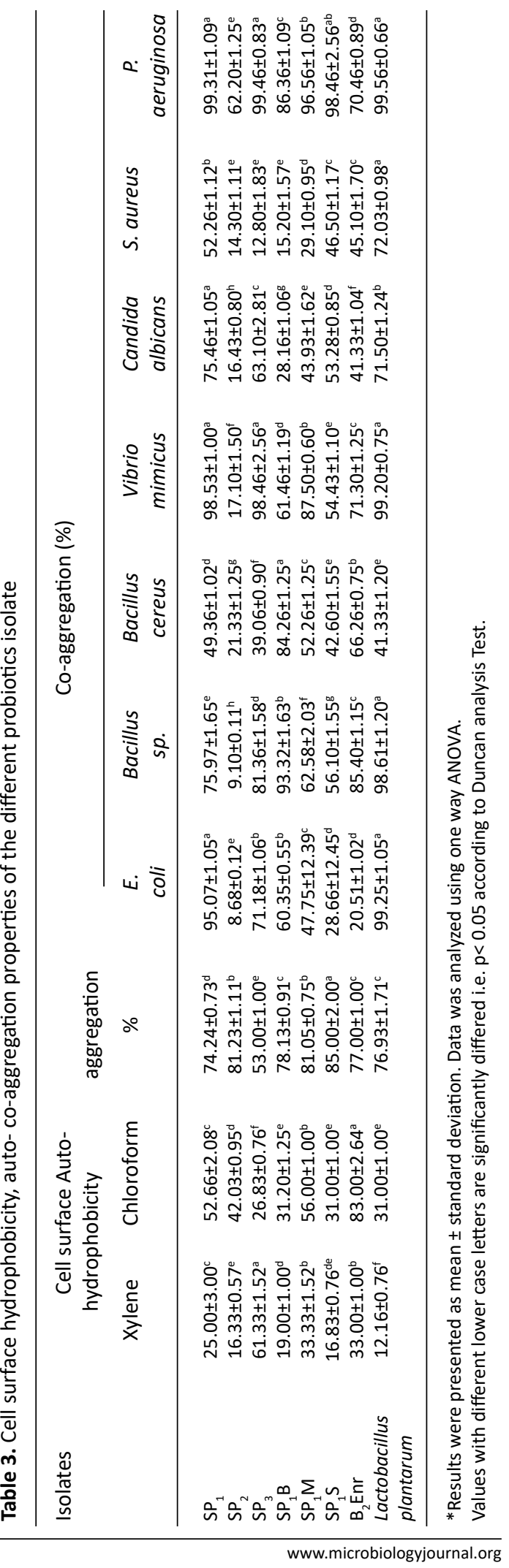


isolate exhibit less co-aggregation property with all the tested microbes including Vibrio mimicus.

Assessment of in vitro biosafety aspects of selected probiotics

Biogenic amines and Gelatinase production by isolates

The $\mathrm{SP}_{1}$ isolate did not produce any biogenic amines against arginine, phenylalanine, tryptophane, lysine amino acids, but it produced biogenic amines against histidine (Table 4). The LB isolate was not found to produce biogenic amines against all the amino acids used. The $\mathrm{SP}_{1} \mathrm{~B}$ and $L$. plantarum showed biogenic amines production against all the amino acids whereas $B_{2}$ Enr did not produce biogenic amines against all amino acids except the arginine.

Further, all the isolates were checked for their geletinase production property (Table $5 b$ ). None of the probiotic isolates showed gelatinase production, as no zone of clearance was found surrounding the colonies on Todd-Hewitt agar plates.

Mucin degradation and Hemolytic activity of Isolates

The mucin degradation property was exhibited by only two probiotic isolates $\mathrm{SP}_{1} \mathrm{M}$ and $\mathrm{SP}_{1} \mathrm{~S}$ which showed clear zones around colonies on medium $B$ (Fig. 1). The other isolates namely $\mathrm{SP}_{1}$, $\mathrm{SP}_{2}, \mathrm{SP}_{3}, \mathrm{~B}_{2} \mathrm{Enr}$, LB and Lactobacillus plantarum did not show mucin degradation.

Table 4. Biogenic amines (BA) production by probiotic isolates

\begin{tabular}{|c|c|c|c|c|c|c|c|c|c|}
\hline Amino acids & $\mathrm{SP}_{1}$ & $\mathrm{SP}_{2}$ & $\mathrm{SP}_{3}$ & $\mathrm{SP}_{1} \mathrm{~B}$ & $\mathrm{SP}_{1} \mathrm{M}$ & $\mathrm{SP}_{1} \mathrm{~S}$ & $\mathrm{~B}_{2} \mathrm{Enr}$ & LB & $\begin{array}{c}L . \\
\text { plantarum }\end{array}$ \\
\hline Histidine & +ve & -ve & +ve & +ve & +ve & -ve & -ve & -ve & +ve \\
\hline Arginine & -ve & +ve & +ve & +ve & +ve & +ve & +ve & -ve & +ve \\
\hline Phenylalanine & -ve & +ve & +ve & +ve & -ve & + ve & -ve & -ve & +ve \\
\hline Tryptophane & -ve & -ve & $-v e$ & +ve & -ve & $-v e$ & -ve & -ve & +ve \\
\hline Lysine & -ve & -ve & -ve & $+v e$ & -ve & -ve & -ve & -ve & +ve \\
\hline
\end{tabular}

${ }^{*}+$ ve :BA production; -ve : No BA production

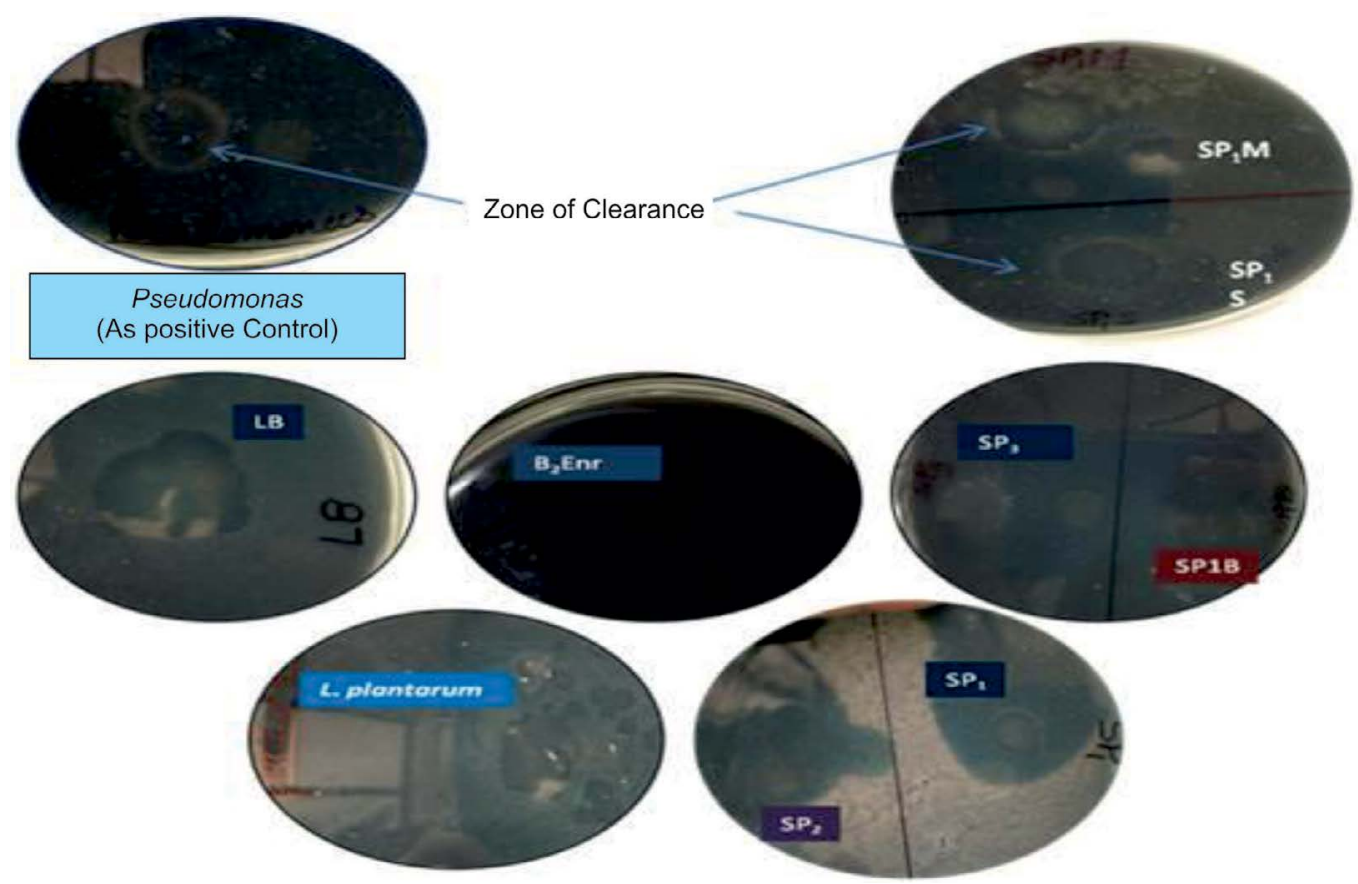

Fig. 1. Mucin degradation by probiotic isolates: SP1M and SP1S showed mucin degradation as observed by clear zone around the colonies. Pseudomonas aruginosa was used as positive control for mucin degradation. 
Table 5. Comparison of probiotic properties and in vitro biosafety aspects of different isolates

(a) Comparison of probiotic properties

\begin{tabular}{lcccccc}
\hline Isolates & $\begin{array}{c}\text { Acid } \\
\text { tolerance }\end{array}$ & $\begin{array}{c}\text { Bile } \\
\text { tolerance }\end{array}$ & $\begin{array}{c}\text { Antibcterial } \\
\text { activity }\end{array}$ & $\begin{array}{c}\text { Auto- } \\
\text { aggregation }\end{array}$ & $\begin{array}{c}\text { Cell surface } \\
\text { hydrophobicity }\end{array}$ & $\begin{array}{c}\text { Co- } \\
\text { aggregation }\end{array}$ \\
\hline $\mathrm{SP}_{1}$ & ++ & +++ & +++ & +++ & ++ & +++ \\
$\mathrm{SP}_{2}$ & +++ & +++ & ++ & +++ & ++ & + \\
$\mathrm{SP}_{3}$ & ++ & ++ & +++ & +++ & ++ & ++ \\
$\mathrm{SP}_{1} \mathrm{~B}$ & +++ & +++ & +++ & +++ & ++ & ++ \\
$\mathrm{SP}_{1} \mathrm{M}$ & ++ & ++ & ++ & +++ & ++ & ++ \\
$\mathrm{SP}_{1} \mathrm{~S}$ & ++ & ++ & +++ & +++ & ++ & ++ \\
$\mathrm{B}_{2}$ Enr & +++ & +++ & +++ & +++ & ++ & ++ \\
L. plantarum & +++ & +++ & +++ & +++ & ++ \\
\hline
\end{tabular}

$*_{+}$Good; ++: very good; +++: Excellent

(b) Comparison of in vitro biosafety aspects

\begin{tabular}{llccccc}
\hline Isolates & $\begin{array}{c}\text { Antibiotic } \\
\text { resistance }\end{array}$ & $\begin{array}{c}\text { Mucin } \\
\text { degradation }\end{array}$ & $\begin{array}{c}\text { Biogenic } \\
\text { amine } \\
\text { production }\end{array}$ & $\begin{array}{c}\text { Hemolytic } \\
\text { activity }\end{array}$ & $\begin{array}{c}\text { Gelatinase } \\
\text { production }\end{array}$ & $\begin{array}{c}\text { Deconjugation } \\
\text { of bile salts }\end{array}$ \\
\hline
\end{tabular}

\begin{tabular}{|c|c|c|c|c|c|c|}
\hline $\mathrm{SP}_{1}$ & + & + & + & + & + & + \\
\hline $\mathrm{SP}_{2}$ & + & + & + & - & + & + \\
\hline $\mathrm{SP}_{3}$ & + & + & + & - & + & + \\
\hline $\mathrm{SP}_{1}^{3} \mathrm{~B}$ & + & + & + & + & + & + \\
\hline $\mathrm{SP}_{1} \mathrm{M}$ & + & - & + & + & + & + \\
\hline $\mathrm{SP}_{1} \mathrm{~S}$ & + & - & + & + & + & + \\
\hline $\mathrm{B}_{2}$ Enr & + & + & + & + & + & + \\
\hline L. plantarum & + & + & + & + & + & + \\
\hline
\end{tabular}

$*_{+}$: Considered as biosafe; - : Considered as non biosafe

The $\beta$-hemolytic activity was exhibited by two probiotic isolates namely $\mathrm{SP}_{2}$ and $\mathrm{SP}_{3}$ as indicated by yellow zones around the colonies (Fig. 2). The other isolates namely $\mathrm{SP}_{1}, \mathrm{SP}_{1} \mathrm{M} \mathrm{SP_{1 }} \mathrm{S}_{2}$ Enr, LB and Lactobacillus plantarum did not show any hemolysis.

Deconjugation of bile salts and Antibiotic resistance of isolates

None of the probiotic isolates were found to exhibit deconjugation property for bile salts, as no precipitation was observed for the colonies (Table 5b).

The antibiotic discs of ampicillin, kanamycin, erythromycin, penicillin-G, vancomycin, rifampicin were used for assessing antibiotic resistance. All the isolates were found to be resistant to penicillin-G. However, they showed susceptibility to ampicillin, kanamycin, erythromycin, vancomycin and rifampicin. The $\mathrm{SP}_{1} \mathrm{~B}$ was moderately susceptible to erythromycin (Fig. 3).

Comparison of probiotic properties and in vitro biosafety aspects of the isolates

Further, the probiotic properties and in vitro biosafety aspects were compared among the isolates (Tables $5 a \& b$, respectively). The comparison of probiotic properties revealed that $\mathrm{SP}_{1} \mathrm{~B}$ and $\mathrm{B}_{2}$ Enr exhibited excellent probiotic characterisitics among the isolates which were also comparable to the standard probiotic $L$. plantarum as well. The comparison of in vitro biosafety aspects of the isolates suggested that $\mathrm{SP}_{1} \mathrm{~B}_{1} \mathrm{SP}_{1}$ and $B_{2} E n r$ can serve as biosafe probiotics, since they passed all the in vitro biosafety assessment criteria used in the present study. 


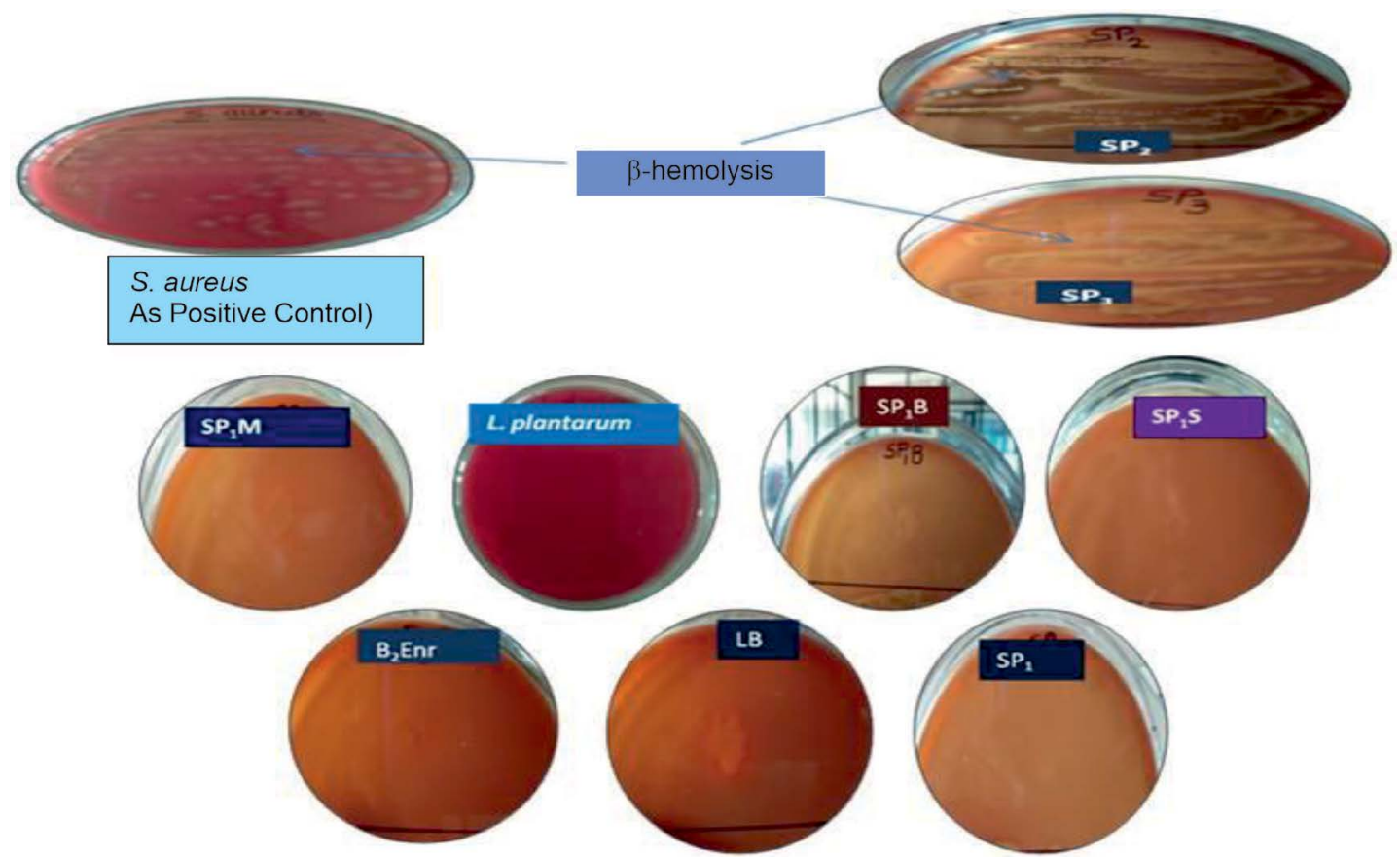

Fig. 2. Hemolytic activity of probiotic isolates: SP2 \& SP3 showed $\beta$-hemolysis. S. aureus was used as positive control culture for $\beta$-hemolysis.

Cultural characteristics and Molecular identification of isolates

The cultural and biochemical aspects were also studied for the selected seven isolates (Table S1 \& S2). The $\mathrm{SP}_{1} \mathrm{M}, \mathrm{SP}_{2}, \mathrm{~B}_{2}$ Enr, $\mathrm{SP}_{1}$, and $\mathrm{SP}_{1} \mathrm{~S}$ were revealed as gram positive cocci, whereas $\mathrm{SP}_{3}$ and $\mathrm{SP}_{1} \mathrm{~B}$ were found to be gram positive bacilli.

The molecular identification of selected probiotic isolates $\left(\mathrm{SP}_{1} \mathrm{~B} \& \mathrm{~B}_{2} \mathrm{Enr}\right)$ which passed the in vitro biosafety aspects was carried out by $16 s r D N A$ sequencing. The results revealed the $S_{1} B$ isolate as Bacillus cereus (MK210172) and $\mathrm{B}_{2} \mathrm{Enr}$ as Staphylococcus epidermidis (MK210234). The $16 s r D N A$ sequences were submitted to GenBankNCBI and the accession numbers MK210172 and MK210234 were obtained for Bacillus cereus and Staphylococcus epidermidis, respectively. The phylogenetic analyses of the probiotic isolates $\left(\mathrm{SP}_{1} \mathrm{~B}\right.$ and $\mathrm{B}_{2}$ Enr) have been shown in Fig. $4 \mathrm{a} \& \mathrm{~b}$.

\section{DISCUSSION}

The breast milk is crucial and fulfills the nutritional requirements for newborns. The human breast milk contains over 700 different types of bacteria, including the genera, Bifidobacteria Micrococci, Lactobacilli,
Staphylococci, Streptococci, Enterococci and Lactococci $^{21}$. Moreover, it also contains prebiotics such as human milk oligosaccharides, which promotes the growth and activity of bacteria ${ }^{22}$. According to analysis of women who take probiotics during pregnancy reduce their child risk of developing allergies. The bacteria isolated breast milk such as Lactobacillus fermentum, Lactobacillus rhamnosus, Lactobacillus gasseri and Enterococcus feacium have been considered as potential probiotic bacteria ${ }^{23}$. Thus, the probiotics isolates of breast milk can be of significant use in different human health conditions and particularly for malnourished children.

The present study evaluated probiotic characteristics as well as biosafety aspects of the isolates obtained from the human breast milk samples. Since, probiotics are administrated orally; they must resist the low $\mathrm{pH}$ of the gastric juice in the stomach. Hence, acid tolerance is one of the important probiotic properties. Previously, probiotic bacteria isolated from human breast milk [L. crispatus, L. fermentum, L. gasseri, Lactobacillus rhamnosus (KF477283) and Lactobacillus casei (KF477282)] showed good acid tolerant property at $\mathrm{pH}^{24,25}$. We found total seven isolates showing 


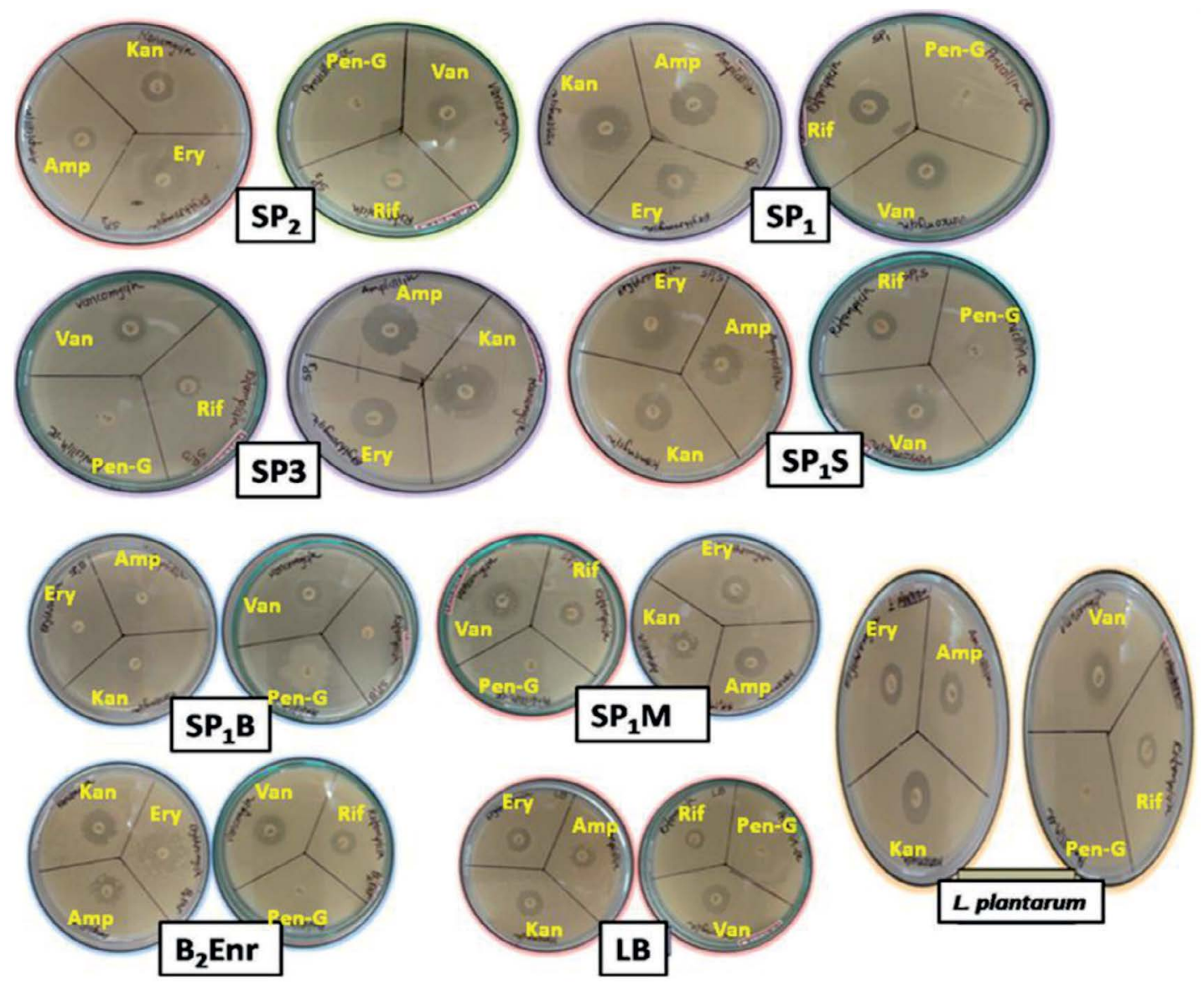

[*Kan: Kanamycin; Amp: Ampicillin; Ery :Erythromycin; Van: Vancomycin; Rif: Rifampicin;

\section{Pen-G: Penicilin-G ]}

Fig. 3. Antibiotic resistance of probiotic isolates shown on Muller Hinton Agar plates. All the probiotic isolates were resistant to Penicillin-G antibiotic. The probiotic isolates were susceptible to Kanamycin, Erythromycin, Vancomycin, Ampicillin, Rifampicin antibiotics.

tolerance to acidic condition $(\mathrm{pH} 3)$ with different time durations. The isolate $\mathrm{B}_{2}$ Enr showed better acid tolerance property as compared to the standard probiotic $L$. plantarum. The secretion of bile extract into the duodenum directly hampers probiotic bacteria. The physiological human bile concentrations range from $0.3 \%$ to $0.5 \%$. Hence, the bile tolerance property of the probiotics must be assessed. Previously, human breast milk isolate $L$. rhamnosus demonstrated $80 \%$ survival rate when subjected to $1.0 \%$ bile concentration. ${ }^{26}$ Interestingly, $\mathrm{SP}_{1} \mathrm{~S}$ isolate from the present study was able to tolerate bile salt up to $1.5 \%$ as compared to L. plantarum; whereas, $\mathrm{SP}_{2}, \mathrm{~B}_{2}$ Enr and
$\mathrm{SP}_{1}$ showed tolerance upto $1 \%$.

The antimicrobial activity against pathogens is also an important attribute for the selection of potential probiotics to maintain a healthy microbial homeostasis in the GIT. Previously, human breast milk isolates, Pediococcus pentosaceus and Lactobacillus casei showed good antibacterial activity ${ }^{27,28}$. In the present study, all isolates showed antibacterial activity against the indicator microorganisms except $\mathrm{SP}_{2}$ and $\mathrm{SP}_{1} \mathrm{M}$. The $E$. coli was found to be highly susceptible to the antibacterial action of the isolates. The antibacterial action of $\mathrm{SP}_{1}, \mathrm{SP}_{1} \mathrm{~B}$ and $\mathrm{SP}_{1} \mathrm{~S}$ was found to be effective against $P$. vulgaris, whereas $\mathrm{SP}_{1^{\prime}}$, 

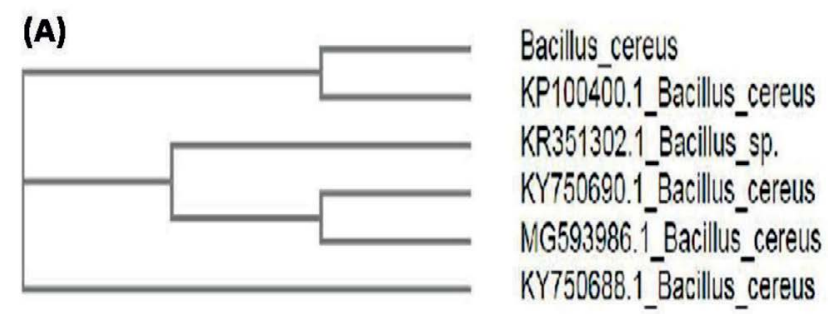

(B)

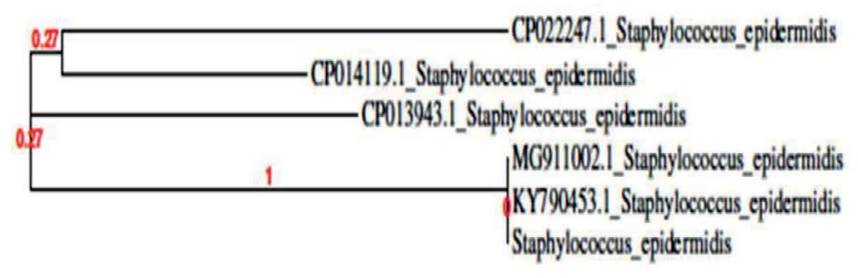

0.3

Fig. 4. (A) Phylogenetic analysis of $S P_{1} B$, from the results of $16 s$ rDNA sequencing and phylogenetic analysis $S P_{1} B$ was identified as Bacillus cereus; $(B)$ Phylogenetic analysis of $B_{2} E n r, B y 16 s$ rDNA sequencing and phylogenetic analysis $\mathrm{SP}_{1} \mathrm{~B}$ was identified as Staphylococcus epidermis.

$\mathrm{SP}_{1} \mathrm{~S}$ and $\mathrm{B}_{2}$ Enr showed good antibacterial activity against $P$. aeruginosa. The $S$. aureus growth was highly susceptible to antibacterial action of $S_{1} P_{1}$, $\mathrm{SP}_{1}, \mathrm{SP}_{2}, \mathrm{SP}_{1} \mathrm{~S}$ and $\mathrm{B}_{2}$ Enr. These results suggest that the isolates possess good antibacterial activity which can vary according to the type of probiotic strain and the pathogenic organism.

Furthermore, the probiotics should possess good cell surface hydrophobicity, auto-aggregation as well as co-aggregation properties with different pathogenic strains. For the attachment of bacteria to host tissue, the hydrophobic outermost surface renders a competitive advantage and also important for bacterial colonization in the human $\mathrm{GIT}^{12,29}$. Moreover, to assess the colonization potential of the organism the hydrophobicity to different hydrocarbons has been considered as an in vitro biochemical marker. ${ }^{30}$ Our results suggested that $\mathrm{SP}_{3}$ possesses highest affinity that is $61 \%$ to xylene as compared to standard probiotic strains Lactobacillus plantarum. With chloroform, $\mathrm{B}_{2} \mathrm{Enr}$ showed highest affinity (i. e. 83\%). The other probiotic isolates also exhibited good affinity with these hydrocarbons indicating that they have good cell surface hydrophobicity. Previous studies have reported that the probiotics showed highest affinity for xylene and relatively more affinity for $\mathrm{n}$-hexadecane in comparison to other strains $\mathrm{s}^{31,32}$. In addition, study by Yadav et al. ${ }^{31}$, suggested that their isolates have good aggregation property. In the present study, the auto-aggregation property of $\mathrm{SP}_{1} \mathrm{~S}, \mathrm{SP}_{1} \mathrm{M}$ and $\mathrm{SP}_{2}$ was found to be the highest (i. e. $85 \%, 81.05 \%$ and $81.23 \%$ respectively). Moreover, the co-aggregation with pathogenic microbes is also important for probiotics since it decreases the activity of the pathogens. Our results of co-aggregation tests are in accordance with the previous studies. ${ }^{12,29}$ The isolates were found to co-aggregate with Escherichia coli, Bacillus sp. , Bacillus cereus, Candida albicans, Vibrio mimicus, Staphylococcus aureus and Pseudomonas aeruginosa. The $\mathrm{SP}_{1} \mathrm{SP}_{3}$ and $\mathrm{SP}_{1} \mathrm{~S}$ isolates showed maximum co-aggregation ability with Pseudomonas aeruginosa. The $\mathrm{SP}_{3}$ exhibited 98\% co-aggregation property with Vibrio mimicus and the $\mathrm{SP}_{1}$ had $95.07 \%$ and $98.53 \%$ co-aggregation ability with Escherichia coli and Vibrio mimicus respectively. The $\mathrm{SP}_{1} \mathrm{~B}$ had $93.32 \%$ co-aggregation ability with Bacillus $s p$. and the $\mathrm{SP}_{1} \mathrm{M}$ had $96.56 \%$ co-aggregation property with Pseudomonas aeruginosa. 
The probiotics must have GRAS property in order to consider it for human consumption and therefore must undergo for in vitro and in vivo biosafety assessment. The present study addressed the different in vitro biosafety aspects. The antibiotic resistance is also a crucial criterion for biosafety. The probiotic must not contain any transferable antibiotic resistance gene. The probiotic bacteria such as Lactobacilli have been found susceptible to penicillin and ampicillin, whereas resistant to vancomycin ${ }^{33}$. Previously, Lactobacillus sp. was reported to be highly resistant to ciprofloxacin, fusidic acid, metronidazole, streptomycin, sulfadiazine, kanamycin, gentamicin, nalidixic acid, bacitracin, cefoxitin and vancomycin ${ }^{33,34}$. In the present study antibiotics such as ampicillin, kanamycin, erythromycin, penicillin-G, vancomycin and rifampicin were used. All probiotic isolates were resistant to penicillin-G; however, they were all susceptible to other antibiotics used in the study. The $\mathrm{SP}_{1} \mathrm{~B}$ was found to be moderately susceptible to erythromycin. Earlier, MudozAtienza et al. ${ }^{35}$ reported that their probiotic strains including Pediococci strains were resistant to erythromycin, tetracycline, ciprofloxacin, norfloxacin, rifampicin, ampicillin, penicillin, gentamycin, streptomycin etc. In another study, the isolates were sensitive to erythromycin, bacitracin, rifampicin, chloramphenicol, ofloxocin, novobiocin and clindamycin; however, they showed high resistance to polymixin $B$, cefuroxime, vancomycin, kanamycin gentamycin, cefazolin, ampicillin, amikacin and cephalothin ${ }^{32}$.

The biogenic amines (BA) are low molecular weight compounds impicated in various biological activities. The food containing higher amount of BA causes human ailments leading to vomiting, hypertension, palpitations, and headache ${ }^{36}$. The decarboxylase or deiminase activity of some probiotics converts amino acids into BA. Moreover, the amino acids catabolism by probiotics may affect quality and safety of foods. Hence, probiotics should not produce large amount of $\mathrm{BA}^{36}$. Previously, study by Singh et al. ${ }^{32}$ suggested that none of their probiotic strains produced BA from the amino acids used, hence they can be considered as safe according to $B A$ production aspect. In this study, most of the probiotic isolates were not found to produce $B A$ when subjected to amino acids such as Histidine, arginine, tryptophane, lysine and phenylalanine. The isolate $\mathrm{B}_{2}$ Enr did not produce $B A$ in the presence of all amino acids except arginine. However, the $\mathrm{SP}_{1} \mathrm{~B}$ and $L$. plantarum produced $\mathrm{BA}$ against all the amino acids. In particular, $\mathrm{SP}_{1}$ did not produce $\mathrm{BA}$ in the presence of arginine, lysine, tryptophane, and phenylalanine, however, it produced $\mathrm{BA}$ in the presence of histidine. The $\mathrm{SP}_{2}$ and $\mathrm{SP}_{1} \mathrm{~S}$ isolates did not produce $B A$ in the presence of histidine, tryptophane and lysine, but they produced BA using arginine and phenylalanine precursors. $\mathrm{SP}_{1} \mathrm{M}$ did not produced $\mathrm{BA}$ using phenylalanine, tryptophane, lysine but it produced $\mathrm{BA}$ in the presence of histidine and arginine. The $\mathrm{SP}_{3}$ produced $B A$ in the presence of histidine, arginine, phenylalanine but it did not produce $B A$ by using lysine and tryptophane. Hence, $\mathrm{SP}_{1}$ and $\mathrm{B}_{2} \mathrm{Enr}$ can be considered as biosafe because they did not produce BA when subjected to different amino acids precursors. However, the isolates which could produce the BA may be further subjected to quantitative evaluation of BA through HPLC to determine the level of BA production.

Furthermore, the mucin degradation is an important criterion for biosafety assessment of probiotics. The probiotic should not degrade mucin. In the present study, except two probiotic isolates $\mathrm{SP}_{1} \mathrm{M}$ and $\mathrm{SP}_{1} \mathrm{~S}$, all probiotic isolates did not degrade mucin. Hence, $\mathrm{SP}_{1} \mathrm{M}$ and $\mathrm{SP}_{1} \mathrm{~S}$ cannot be considered as safe. In one previous study, none of the probiotic isolates degraded mucin ${ }^{32}$. In addition, the hemolytic activity of bacteria is an indication of pathogenicity. Probiotics must not show hemolytic activity. In this study, all probiotic isolates did not show hemolysis on blood agar, except the two probiotic isolates $\mathrm{SP}_{2}$ and $\mathrm{SP}_{3}$ which showed $\lambda$-hemolysis. Hence, $\mathrm{SP}_{2}$ and $\mathrm{SP}_{3}$ cannot be considered as safe. One previous study suggested that Bacillus clausii UBBC07 did not show hemolytic activity and can be considered as safe probiotic ${ }^{37}$. Similarly, in another study ${ }^{32}$ none of their isolates showed hemolytic activity. The gelatinase production is also an indication of bacterial virulence ${ }^{38}$. Probiotics must not produce gelatinase. In the present study, none of the probiotic isolates produced gelatinase and our results are in accordance with the previous study $^{32}$. The deconjugation of bile salts exerted by microbes may promote many alterations in 
physiochemical properties. Hence, probiotics should not deconjugate bile salts present in intestine ${ }^{39}$. In the present study, none of the probiotic isolates showed deconjugation of bile salts and our results are in line with those reported previously ${ }^{32}$.

Further, we compared the in vitro biosafety aspects of all our isolates which revealed that three probiotic isolates namely, $\mathrm{SP}_{1} \mathrm{~B}, \mathrm{~B}_{2} \mathrm{Enr}$ and $\mathrm{SP}_{1}$ can be considered as safe as they passed all above mentioned criteria of biosafety aspects. Moreover, these isolates possess potent probiotic properties among other isolates. In addition, these probiotic isolates were found to exhibit good cell surface hydrophobicity, good auto-aggregation as well as good coaggregation property with pathogenic organisms. The molecular characterization of $\mathrm{SP}_{1} \mathrm{~B}$ and $\mathrm{B}_{2} \mathrm{Enr}$ by $16 s r D N A$ sequencing suggested $\mathrm{SP}_{1} \mathrm{~B}$ as Bacillus cereus (MK210172) and $\mathrm{B}_{2}$ Enr as Staphylococcus epidermidis (MK210234). Among the currently used probiotic products, mostly probiotic strains are bacterial spore formers such as genus Bacillus, which has been shown to prevent GIT disorders ${ }^{40}$. The $B$. cereus has been used as a potential probiotic in human medicine and livestock production as well ${ }^{41}$. The $B$. cereus CenBiot was proposed as a suitable candidate for probiotic elaboration ${ }^{42}$ and was examined in farms where it controlled diarrhoea and feed conversion in pigs ${ }^{43}$. In the EU two Bacillus products have been licensed for use in animals viz. Toyocerin and BioPlus $2 \mathrm{~B}^{44,45}$; wherein the Toyocerin consisting of $B$. cereus var toyoi was found extremely safe for animal use. Though, till now S. epidermidis has been considered as an opportunistic pathogen, the recent studies reveal that $S$. epidermidis plays an important role in skin homeostasis via suppressing inflammatory cytokines and producing antimicrobial molecules to inhibit skin pathogens ${ }^{46}$. In addition, one recent study has reported the strong skincare effect of a probiotic skin product consisting of $S$. epidermidis ${ }^{47}$. Moreover, study by Wang et al. ${ }^{48}$ reported that $S$. epidermidis inhibits the growth of Propionibacterium acnes and can be implicated as probiotics in acne vulgaris. Recently, a review article has highlighted the role of $S$. epidermidis, Lactobacillus and Bifidobacterium sp. in the treatment of atopic dermatitis ${ }^{49}$. (Mottin and Suyenaga, 2018). However, many of these studies were conducted in vitro, and more detailed research should be performed in order to prove the efficacy and safety of these probiotics.

\section{CONCLUSION}

Overall, the present study found that the three isolates namely $\mathrm{SP}_{1} \mathrm{~B}$ (B. cereus; MK210172), $\mathrm{B}_{2}$ Enr (S. epidermidis; MK210234) and SP obtained from human breast milk can be considered as potential probiotics. These isolates have shown better probiotic activities as compared to standard probiotic $L$. plantarum. Though, previously $B$. cereus and $S$. epidermidis were considered as opportunistic pathogens; the present study findings along with the other above mentioned studies suggest the use of these bacterial strains to be safe and beneficial. However, these bacterial strains must be assessed further for in vivo biosafety aspects using animal models for its consideration of human and/or animal use.

\section{ACKNOWLEDGMENTS}

We would like to thank all the volunteers who participated in this study and provided the milk samples. We are thankful to Uka Tarsadia University, Bardoli, Gujarat, India for providing necessary research facilities to conduct the study.

\section{CONFLICTS OF INTEREST}

The authors declare that there is no conflict of interest.

\section{AUTHORS' CONTRIBUTIONS}

All authors listed have made a substantial, direct and intellectual contribution to the work, and approved it for publication.

\section{FUNDING}

None.

\section{DATA AVAILABILITY}

The datasets generated and/or analysed during the current study are available in the GenBank-NCBI database repository, Accession No: MK210172 (Bacillus cereus); MK210234 (Staphylococcus epidermidis).

\section{ETHICS STATEMENT}

All procedures performed in this study involving human participants were in accordance 
with the ethical standards of the InstitutionalHuman Research Ethical Committee (HREC), Maliba Pharmacy College, Uka Tarsadia University, Bardoli, Gujarat, India and with the 1964 Helsinki declaration and its later amendments or comparable ethical standards. All subjects signed informed consent.

\section{REFERENCES}

1. FAO/WHO. Guidelines for the evaluation of probiotics in food. 2002.

2. Gourbeyre P. , Denery S. \& Bodinier M. Probiotics, prebiotics, and synbiotics: impact on the gut immune system and allergic reactions. J. Leukoc. Biol. , 2011; 89: 685-695.

3. Macpherson A. J., Harris N. L. Interactions between commensal intestinal bacteria and the immune system. Nat Rev Immunol. , 2004; 4: 478-485.

4. Guarner F. \& Malagelada J. R. Gut flora in health and disease. Lancet, 2003; 361: 512-519.

5. Cebra JJ. Influences of microbiota on intestinal immune system development. Am. J. Clin. Nutr. 1999; 69: 1046S-1051S.

6. Dwivedi M. , Kumar P., Laddha N. C. \& Kemp E. H. Induction of Regulatory T Cells: A Role for Probiotics and Prebiotics to Suppress Autoimmunity. Autoimmunity Rev. , 2016; 15(4): 379-392.

7. Favier C. F., DeVos W. M. \& Akkermans A. D. Development of bacterial and bi dobacterial communities in feces of newborn babies. Anaerobe, 2003; 9: 219-229.

8. Fernבndez L., Langa S. , Marton V., Maldonado A. , Jim'nez E. , Marton R. \& Rodraguez J. M. The human milk microbiota: origin and potential roles in health and disease. Pharmacol Res. , 2013; 69(1): 1-10.

9. Olivares M. , Diaz-Ropero M. P. , Martin R. , Rodriguez J. M. \& Xaus J. Antimicrobial potential of four Lactobacillus strains isolated from breast milk. J. Appl. Microbiol. , 2006; 101: 72-79.

10. Kumar M. , Ghosh M. \& Ganguli A. Mitogenic response and probiotic characteristics of lactic acid bacteria isolated from indigenously pickled vegetables and fermented beverages. World J. Microbiol. Biotechnol., 2012; 28: 703-711.

11. Rickard A. H. , Gilbert P. , High N. J., Kolenbrander P. E. \& Handley P. S. Bacterial coaggregation: an integral process in the development of multi-species bio Ims. Trends Microbiol. , 2003; 11: 94-100.

12. Garcoa-Cayuela T. , Korany A. M. , Bustos I. , deCadio anos LPG, Requena T, Pelבez $\mathrm{C}$ et al. Adhesion abilities of dairy Lactobacillus plantarum strains showing an aggregation phenotype. Food Res. Int. , 2014; 57: 4450.

13. Geertsema-Doornbusch G. I. , Van der Mei H. C. \& Busscher H. J. Microbial cell surface hydrophobicity the involvement of electrostatic interactions in microbial adhesion to hydrocarbons (MATH). J. Microbiol Methods. , 1993; 18(1): 61-68.

14. Tomas M. \& Nader M. Effect of culture conditions on growth and autoaggregation ability of vaginal
Lactobacillus johnsoni CRL 1294. J. Appl. Microbiol. , 2005; 99: 1383-1391.

15. Handley P. S. , Harty D. W. , Wyatt J. E., Brown C. R., Doran J. P. \& Gibbs A. C. A comparison of the adhesion, coaggregation and cell-surface hydrophobicity properties of fibrillar and fimbriate strains of Streptococcus salivarius. J. Gen. Microbiol. , 1987; 133: 3207-3217.

16. Bover-Cid S. \& Holzapfel W. Improved screening procedure for biogenic amine production. Int. J. Food Microbiol. , 1999; 53: 33-41.

17. Eatson T. J. \& Gasson M. J. Molecular Screening of Enterococcus Virulence Determinants and Potential for Genetic Exchange between Food and Medical Isolates. Appl. Environ. Microbiol. , 2001; 67(4): 1628-1635.

18. Romanenko L. A. , Uchino M. , Kalinovskaya N. I. , Mikhailov V. V. Screening of antimicrobial, hemolytic activities. Microbiol. Res. , 2008; 163: 633-644.

19. Noriega L., Cuevas I. , Margolles A. \& de los ReyesGavilan C. G. Deconjugation and bile salts hydrolase activity by Bifidobacterium strains with acquired resistance to bile. Int. Dairy J. , 2006; 16: 850-855.

20. Bauer A. W. , Kirby W. M. M. , Sherris J. C. \& Turck M. Antibiotic susceptibility testing by a standardized single disk method. Am. J. Clin. Pathol. , 1966; 45(4): 493-496.

21. Cabrera-Rubio R. , Collado M. C. , Laitinen K. , Salminen S., Isolauri E. , Mira A. The human milk microbiome changes over lactation and is shaped by maternal weight and mode of delivery. Am. J. Clin. Nutr. , 2012; 96(3): 544-51.

22. Martin R. , Langa S. , Reviriego C. , Jimenez E. , Marin M. L. , Xaus J., et al. Human milk is a source of lactic acid bacteria for the infant gut. J. Pediatr. , 2003; 143: 754-758.

23. Martin R, Langa S, Reviriego C, Jimenez E, Marin LM, Olivares $\mathrm{M}$, et al. The commensal microflora of human milk: New perspectives for food bacteriotherapy and probiotics. Trends Food Sci. Technol. , 2004; 15: 121127.

24. Kozak K. , Charbonneau D. , Sanozky-Dawes R. \& Klaenhammer T. Characterization of bacterial isolates from the microbiota of mothers' breast milk and their infants. Gut. Microbes. , 2015; 6(6): 341-351.

25. Kavitha J. R. \& Devasena T. Isolation, Characterization, Determination of Probiotic Properties of Lactic Acid Bacteria from Human Milk. IOSR J Pharm. Biol. Sci. , 2013; 7(3): 01-07.

26. Rajoka M. S. R. , Mehwish H. M. , Siddiq M. , Haobin Z. , Zhu J. , Yan L., et al. Identification, characterization, and probiotic potential of Lactobacillus rhamnosus isolated from human milk. LWT - Food Sci. Technol. , 2017; 84: 271-280.

27. Osmanagaoglu O. , Kiran F. \& Ataoglu H. Evaluation of in vitro Probiotic Potential of Pediococcus pentosaceus OZF Isolated from Human Breast Milk. Probiotics Antimicrob. Proteins, 2010; 2(3):162-74.

28. Shokryazdan P. , Sieo C. C. , Kalavathy R. , Liang J. B. , Alitheen N. B. , Jahromi M. F. , et al. Probiotic Potential of Lactobacillus Strains with Anti-microbial Activity against Some Human Pathogenic Strains. BioMed Res. Int. , 2014; 2014: 1-16.

29. Di Bonaventura G. , Piccolomini R., Paludi D. 
, D'orio V. , Vergara A., Conter M. \& lanieri A. Influence of temperature on biofilm formation by Listeria monocytogenes on various food contact surfaces: relationship with motility and cell surface hydrophobicity. J. appl. Microbiol. , 2008; 104(6): 1552-1561.

30. Rosenberg M. , Gutnick D. \& Rosenberg E. Adherence of bacteria to hydrocarbons: a simple method for measuring cell surface hydrophobicity. FEMS Microbiol. Lett. , 1980; 9(1): 29-33.

31. Yadav R. , Puniya A. K. \& Shukla P. Probiotic Properties of Lactobacillus plantarum RYPR1 from an Indigenous Fermented Beverage Raabadi. Front. Microbiol. , 2016; 7: 1683.

32. Singh T. P. , Malik R. K. \& Renuka G. K. Safety assessment and evaluation of probiotic potential of Lactobacillus reuteri strains under in vitro conditions. Int. J. Curr. Microbiol. Appl. Sci. , 2014; 3(2): 335-348.

33. Blandino G., Milazzo I. \& Fazio D. Antibiotic susceptibility of bacterial isolates from probiotic products available in Italy. Microb. Ecol. Health Dis. 2008; 20: 199-203.

34. Kastner S., Perreten V. , Bleuler H. , Hugenschmidt G. , Lacroix C. \& Meile L. Antibiotic susceptibility patterns and resistance genes of starter cultures and probiotic bacteria used in food. Syst. Appl. Microbiol. , 2006; 29(2): 145-55.

35. Mudoz-Atienza E. , Gqmez-Sala B. , Araתjo C. , Campanero C. , Del Campo R. , Hernבndez P. E. , et al. Antimicrobial activity, antibiotic susceptibility and virulence factors of lactic acid bacteria of aquatic origin intended for use as probiotics in aquaculture. $B M C$ Microbiol. , 2013; 13(1): 15.

36. Lonvaud-Funel A. Biogenic amines in wines: role of lactic acid bacteria. FEMS Microbiol. Lett. , 2001; 199: 9-13.

37. Lakshmi S. G. , Jayanthi N. , Saravanan M. \& Sudha Ratna M. Safety assesment of Bacillus clausii UBBC07, a spore forming probiotic. Toxicol Rep. , 2017; 4: 62-71.

38. Thurlow L. R. , Thomas V. C. , Narayanan S. , Olson S. , Fleming S. D. \& Hancock L. E. Gelatinase Contributes to the Pathogenesis of Endocarditis Caused by Enterococcus faecalis. Infect. Immun. , 2010; 78(11): 4936-4943.

39. Dunne C. , O'Mahony L, Murphy L, Thornton G, Morrissey D, O'Halloran S, et al. In vitro selection criteria for probiotic bacteria of human origin: correlation with in vivo findings. Am. J. Clin. Nutr., 2001; 73: 386S-92S.
40. Hong H. A., Duc L. H. \& Cutting S. M. The use of bacterial spore formers as probiotics. FEMS Microbiol. Rev. , 2005; 29: 813-835.

41. Elshaghabee F. M. F. , Rokana N. , Gulhane R. D. , Sharma C. \& Panwar H. Bacillus As Potential Probiotics: Status, Concerns, and Future Perspectives. Front. Microbiol. , 2017; 8: 1490.

42. Gil-Turnes C. , Freitas dos Santos A. , Weykamp da Cruz F. , Monteiro A. V. Properties Of The Bacillus Cereus Strain Used In Probiotic CenBiot. Revista de Microbiologia, 1999; 30: 11-14.

43. Zani J. L., da Cruz F. W. , dos Santos A. F. \& Gil-Turnes C. Effect of probiotic CenBiot on the control of diarrhoea and feed efficiency in pigs. J. Appl. Microbiol. , 1998; 84: 68-71.

44. SCAN. Assessment by the Scientific Committee on Animal Nutrition (SCAN) of a microorganism product: Esporafeed Plus. European Commission, Health and Consumer Protection Directorate-General. (SCAN) Scientific Committee on Animal Nutrition. 1999, Available from http://europa. eu. int/comm/food/fs/ sc/ scan/out39_en. pdf.

45. SCAN. Report of the Scientific Committee on Animal Nutrition on product BioPlus 2B for use as feed additive. European Commission, Health and Consumer Protection Directorate-General. (SCAN) Scientific Committee on Animal Nutrition. 2000, Available from: http://europa. eu. int/comm/food/fs/sc/scan/ out49_en. pdf.

46. Lai Y. , Di Nardo A., Nakatsuji T. , Leichtle A., Yang Y., Cogen A. L. et al. Commensal bacteria regulate Toll-like receptor 3-dependent inflammation after skin injury. Nat. Med. , 2009; 15: 1377-1382.

47. Dekio I. Clinical effect of novel probiotic product for the skin containing Staphylococcus epidermidis isolated from customers. Conference Proceedings of IPC 2016. Paper presented at the International Scientific Conference on Probiotics and Prebiotics, 2016; Budapest (p. 21.).

48. Wang Y., Kuo S., Shu M. , Yu J., Huang S., Dai A. , et al. Staphylococcus epidermidis in the human skin microbiome mediates fermentation to inhibit the growth of Propionibacterium acnes: Implications of probiotics in acne vulgaris. App/ Microbiol Biotechnol., 2014; 98(1): 411-424.

49. Mottin V. H. M. \& Suyenaga E. S. An approach on the potential use of probiotics in the treatment of skin conditions: acne and atopic dermatitis. Int. J Dermatol., 2018; 57(12): 1425-1432. 